DOCUMENTO DE REFLEXIÓN
NO DERIVADO DE INVESTIGACIÓN
Recibido: 04/02/2019

Revisado: 01/03/2019

Aprobado: 05/04/2019

\title{
La Carta de Jamaica. Inventario de un genocidio y análisis del sueño frustrado de libertad
}

The Jamaican Letter. Record of genocide and analysis of the frustrated dream of freedom

\author{
Carlos Arboleda González \\ Economista, Ensayista, Ex secretario de cultura del Departamento de Caldas \\ Email: carbol53@gmail.com
}

Doi: https://doi.org/10.22267/rceilat.194445.28

\section{Resumen}

Pensamos que la Carta de Jamaica es el documento central del sueño bolivariano porque fue redactada en plenas guerras de independencia y porque preludia el futuro político de la América mestiza. Aquí demostraremos que el inventario del genocidio se ha quedado corto si sólo ha sido referido desde la Conquista y también, en segundo lugar, que el análisis político de Simón Bolívar, en 1815, posee toda su vigencia y urgencia. José Carlos Mariátegui, el gran pensador peruano, ya había escrito, al comienzo del siglo XX, que habíamos cambiado el feudalismo español por el criollo y el encomendero por el tiranuelo.

La Carta de Jamaica es un documento histórico, político y literario al que damos una relevancia capital en la vida y en la obra de Simón Bolívar. Y tiene un valor para nosotros como texto erudito, como manifiesto político que ayuda también al estudioso de la vida del libertador para entender su propia evolución política y personal. En este ensayo nos hemos guiado por los lineamientos expresados en la segunda parte de este escrito que tiene que ver con el inventario del genocidio y con el análisis de la posible evolución política de Indoamérica.

Palabras clave: Carta de Jamaica; Historia; América; América mestiza.

\begin{abstract}
We believe that the Charter of Jamaica is the central document of the Bolivarian dream because it was drafted in the midst of wars of independence and because it preludes the political future of mixed America. Here we will show that the inventory of the genocide has fallen short if it has only been referred since the Conquest and also, secondly, that the political analysis of Simon Bolivar, in 1815, has all its validity and urgency. José Carlos Mariátegui, the great Peruvian thinker, had already written, at the beginning of the twentieth century, that we had changed Spanish feudalism to Creole and encomendero for tyranny.
\end{abstract}


The Charter of Jamaica is a historical, political and literary document to which we give a capital relevance in the life and work of Simón Bolívar.

And it has value for us as a scholarly text, as a political manifesto that also helps the scholar of the life of the liberator to understand his own political and personal evolution. In this essay we have guided by the guidelines expressed in the second part of this brief that has to do with the inventory of the genocide and the analysis of the possible political evolution of Indoamerica.

Key words: Letter from Jamaica; History; America; Mixed America.

\section{Historia y literatura en la Carta de Jamaica}

A comienzos del siglo XIX la libertad empieza a estrenarse sobre el Viejo Mundo y se ensaya sobre el Nuevo: el despotismo ilustrado cede su papel histórico al naciente Estado moderno, al protagonismo del ciudadano, a la epopeya de los derechos ciudadanos. Se habla por todas partes de la naturaleza humana como si el propio individuo estuviera apenas por demostrarse. Casi podemos decir que existe un sujeto nuevo para la historia y para la literatura. Ya es difícil que los autores, los hombres eruditos, los filósofos, los políticos, se ocupen de la moral, de la religión o de la historia sagrada. Los vemos a todos ocupados en diseñar proyectos sobre la vida porque el ser humano está ensayando su individualidad y su autodeterminación sobre la tierra.

Nosotros estábamos acostumbrados a la lectura de los enciclopedistas del siglo XVIII: su concepto de la vida y del hombre inspirado en un sano racionalismo y en la instigación de un regreso a la naturaleza de los costumbres, ideas expresadas en el Emilio de Rouseau. Es un criticismo desde moderado hasta extremista de todo lo que tuviera que ver con jerarquías religiosas y despotismos, como ocurre en la literatura de Voltaire, Diderot y D'Alembert. Pero ahora tenemos que leer los documentos bolivarianos que tienen que ver con un sueño de libertad mítico, protohistórico, porque el siglo XIX es el tiempo en el que se redescubre al hombre, así como el siglo XV había redescubierto al mundo. Pero nuestro Renacimiento se hace en medio de la incertidumbre $\mathrm{y}$ de las nacientes guerras fraticidas, porque el Nuevo Mundo nació enfermo e iría a ser destinado a cambiar de amos: del imperialismo español al imperialismo norteamericano. Estas ideas expresadas premonitoriamente en la Carta de Jamaica han surgido más bien del literato y del pensador, del analista, del hombre racional, que del mitómano en que se convertiría luego con delirios de emperador, permitiendo que su emocionalismo se sobrepusiera al equilibrio de sus facultades, capaces de medir la evolución política y económica de los pueblos, en aquel momento, en 1815.

Bolívar hace en este manifiesto alusiones al pasado demostrando su conocimiento de la historia y su gusto por la enseñanza moral que dejan los griegos. No puede entender cuál sea el sentido del regreso de Quetzalcóatl y 
hace una extensa comparación entre la actitud del Viejo Mundo, ante los reyes y monarcas, y la que se adopta acá en América, frente a los caciques, a los zipas, toquis, ulmenes y demás soberanos aborígenes. Es notable la intención de Simón Bolívar de adornar este documento para probar que siendo hijos de España no se trata de cobrar con sangre las afrentas del invasor. Es fundamental la idea central de este documento en la que se insiste en la necesidad de educar más que la de gobernar; inspirándose en Montesquieu cita la célebre frase: Es más difícil sacar a un pueblo de la servidumbre que subyugar uno libre.

La Carta de Jamaica es un ejemplo de aquel tipo de documentos en los que se alternan por igual el escritor, el historiador y el político, atribuidos a César, a Napoleón, a Alejandro, a los grandes civilizadores. Pero a la vez es un escrito que preludia la voluntad del tirano que quiere disponer de un nuevo mundo con su voluntad de padre, de rey y de emperador, así como lo hiciera Napoleón con Europa. La Carta de Jamaica son unas reflexiones más sobre la intención del poder. Pero, para nosotros que somos lectores desprevenidos de aquella circunstancia histórica que ahora nos parece tan lejana, Simón Bolívar se nos antoja un caballero, de una educación clásica y de una cultura superlativa. Es como aquellos condotieros del Renacimiento, como aquellos señores de las ciudades-estado que gustaban del humanismo y de la espada para instaurar nuevas aristocracias, sólo que Simón Bolívar, verdaderamente, amaba el sueño de la libertad y soñó y escribió sobre la construcción del Nuevo Mundo, en esta vasta zona de la tierra, sueño impedido en forma renovada por el egoísmo de los tiranos y de la barbarie. La conciencia del pueblo del Nuevo Mundo ha sido abortada porque el espíritu de las leyes y el de la libertad fueron malversados por la eterna lucha, por la supremacía económica de las cuales han dependido las ideologías políticas. Pero sigamos leyendo la Carta de Jamaica.

\section{La Carta de Jamaica: un inventario de la fatalidad del Nuevo Mundo}

Existe una pregunta en este documento referida al Libertador sobre las formas de gobierno que deberían ser adoptadas en América. En esta carta, dirigida por un hombre que ensaya a ser el redentor político de medio mundo a un ciudadano del Norte que está interesado en esta gesta revolucionaria y libertaria, existen dos momentos: el primero es el inventario y el empadronamiento del genocidio del español y el segundo es el análisis de las voluntades de evolución política de las tierras americanas que van de México hasta la Patagonia.

\section{El genocidio indoamericano}

En aquella época era difícil someter al análisis racional la condición geopolítica del pueblo americano. Bolívar se apoya en Humboldt para hacer la descripción de estas tierras y aun así desconoce la posibilidad de ser objetivo: El mismo barón de Humboldt, con su universalidad de pensamientos teóricos y prácticos, apenas lo haría con exactitud porque aunque una parte de la estadística y revolución de América es conocida, me atrevo a asegurar que la mayor está cubierta de tinieblas y, por 
consecuencia, sólo se pueden ofrecer conjeturas más o menos aproximadas, sobre todo en lo relativo a la suerte futura y a los verdaderos proyectos de los americanos (Bolívar, 1993, p. 17). Y estamos a 6 de septiembre de 1815 , en este Nuevo Mundo que ya ha sufrido tres siglos de destrucción. Aquí nos encontramos con Simón Bolívar tratando de presentar la situación a Henry Cullen, ciudadano de Jamaica, que quiere saber sobre la situación americana. Respecto a nuestra primera tesis, según la cual la carta de Jamaica es el primer censo del genocidio americano, podemos aportar como idea la siguiente: que podía contarse como habitantes de la América unos diez y siete millones; que la Nueva España, según el barón de Humboldt, tenía unos 7.800.000 con inclusión de Guatemala, territorio que se contaba incluyendo los Estados Unidos Mexicanos; que en 1812 Venezuela contaba con cerca de un millón de habitantes y que un terremoto mató más o menos la cuarta parte, además de la espada, el hambre, la peste, las peregrinaciones; excepto el terremoto, todo resultado de la guerra (Bolívar, 1993, p. 19). Del virreinato del Perú afirma que su población ascendía, en aquella época, a millón y medio de habitantes; que el reino de Chile a ochocientos mil almas; de la Nueva Granada, el corazón de la América, como la denomina, afirma que tiene, exceptuando el reino de Quito, dos millones y medio de habitantes; y así, datos de este empadronamiento de las Américas van siendo referidos paralelos a los de su propia extinción. O sea, que a 300 años del descubrimiento las guerras de independencia siguen minando la población mestiza y aborigen.
José Carlos Mariátegui en sus ensayos de interpretación de la realidad peruana, escribe: La población del imperio inkaico, conforme a cálculos prudentes, no era menor de diez millones. Hay quienes la hacen subir a doce y aun a quince millones. La conquista fue, ante todo, una tremenda carnicería... (Mariátegui, s.f., p. 26). Ya existen en la actualidad suficientes documentos sobre esta realidad. Pero nos falta asumir, con toda honestidad, que desde 1815 a esta época estos despropósitos no han cesado por culpa de las guerras fraticidas. Sistemas de dominación sustentados por la barbarie y la violencia se han perpetuado hasta nuestros días, convirtiendo el sueño americano de la Carta de Jamaica en una página suelta sobre la libertad y la justicia. Toda la América mestiza sigue viviendo sobre la fatalidad de la sangre derramada entre hermanos. La guerra de la independencia insinuó la guerra bipartidista entre conservadores y reformadores. Mariátegui lo dice, en este ensayo, que la guerra de la independencia no resolvió el problema ni del negro, ni del indio, ni del esclavo, ni del explotado. Y retomando a Bolívar, nos quedó grande la tarea de crecer como Estados libres y soberanos porque nuestra realidad sigue siendo la de países productores, esclavos de los dueños de los bienes del capital. Montesquieu sigue teniendo razón porque tal vez conquistamos la libertad pero no nos hemos evadido de la servidumbre.

El pueblo indoamericano siguió creciendo después de las guerras de la independencia como respondiendo al reclamo de mano de obra abundante que remplazará el pico y pala de 
Arboleda González, C. (2019). La Carta de Jamaica. Inventario de un genocidio y análisis del sueño frustrado de libertad. Revista Estudios Latinoamericanos, 44-45, 103-110.

los socavones con la mano de pulpo del obrero, para las fábricas y para la construcción de carreteras y ciudades, único crecimiento en esta enorme despensa de América. El genocidio nunca se detuvo, ni la fatalidad. En este sentido Bolívar tenía toda la razón cuando insistía en la necesidad de educación y en el peligro que representaba el excesivo poder: En tanto que nuestros compatriotas no adquieran lo talentos $y$ virtudes políticas, que distinguen a nuestros hermanos del Norte, los sistemas enteramente populares, lejos de sernos favorables, temo mucho que venga a ser nuestra ruina. Desgraciadamente estas cualidades pueden estar muy distantes de nosotros en el grado que se requiere; y por el contrario, estamos dominados de los vicios que se contraen bajo la dirección de una nación como la española, que solo ha sobresalido en fiereza, ambición, venganza y codicia (Bolívar, 1993. p. 26). Tal parece que heredamos este tipo de rasgos y no el espíritu de libertad y esto, desde luego, se ha visto reflejado en nuestras instituciones y en nuestra historia política.

Mariátegui, en sus ensayos ya referenciados, es muy claro: El Virreinato aparece menos culpable que la república. Al Virreinato le corresponde, originalmente, toda la responsabilidad de la miseria y la depresión de los indios (...) Mientras que el Virreinato era un régimen medieval y extranjero, la República es formalmente un régimen peruano y liberal. Tiene, por consiguiente, la República deberes que no tenía el Virreinato. A la República le tocaba elevar la condición del indio. $Y$ contrariando este deber ha pauperizado al indio, ha agravado su depresión y ha exasperado su miseria. La República ha significado para los indios la ascensión de una nueva clase dominante que se ha apropiado sistemáticamente de sus tierras. En una raza de costumbre y de alma agraria, como la raza indígena, este despojo ha constituido una causa de disolución material y moral. La tierra ha sido siempre toda la alegría del indio. El indio ha desposado la tierra. Siente que «la vida viene de la tierra» $y$ vuelve a la tierra. Por ende, el indio puede ser indiferente a todo, menos a la posesión de la tierra que sus manos y su aliento labran y fecundan religiosamente. La feudalidad criolla se ha comportado, a este respecto, más ávida y más duramente que la feudalidad española (Mariátegui, s.f., p. 27-28). Estas mismas consideraciones pueden ser aplicadas al resto de la América mestiza. La Carta de Jamaica, no previó esta nueva desgracia proveniente de los mismos oprimidos para con los propios. Y después de Mariátegui iqué diremos ahora de los desplazados en Colombia, de la miseria centroamericana después de la guerra, de la regresión institucional en el Perú y de los militarismos de siempre en el sur de América!

Lo cierto es que en la América insular, Cuba, es la única que ha hecho realidad el sueño de independencia y eso apenas desde 1959, porque allí la reconquista de la dignidad se ha iniciado con el reconocimiento de los propios. De las cifras aportadas por Humboldt, y anotadas en esta carta, hasta nuestros días, existe un abismo numérico de 1 a 1000. Y los problemas de evolución política y económica siguen siendo los mismos desde México hasta la Patagonia, mientras que 
el modelo cubano permanece siendo aislado: Cuba tiene doce millones de habitantes; Colombia 40 millones de personas y 5 millones de desplazados. En el Perú la población indígena se ha fundido con el de las ciudades en un nuevo criollismo de miseria, lo mismo que en Bolivia y Ecuador. Los muertos de Centroamérica en las guerras de Salvador y de Nicaragua son incontables. ¿A quién dirigiremos ahora esta nueva Carta de Jamaica y quién la podrá redactar, pensando en la libertad americana?

\section{Evolución política de América en la Carta de Jamaica}

El futuro político de la América Latina es tan incierto ahora como lo era en 1815. Y se ha cumplido el presagio de Bolívar relacionado con los excesos de poder y la falta de una cultura política. Demasiada democracia degeneró en tiranía, en guerras partidistas y los gobiernos de este lado del mundo se volvieron entreguistas con el amo del norte. Mariátegui sigue teniendo razón: la mentira de nuestras repúblicas le ha sido favorable a los colonos del Norte, los cuales han favorecido, por ejemplo en Colombia, el sueño bolivariano de los tres poderes: el ejecutivo, el legislativo, y el judicial, según el cual somos los modelos constitucionales del Tercer Mundo, pero no hemos resuelto ni el problema de la libertad ni el de las leyes que tengan que ver con los derechos humanos. Y ya sabemos también el destino del Istmo de Panamá, cuyo canal apenas fue reintegrado a los panameños hace poco más de un año. Pero la democracia sigue siendo el sistema imperante desde México hasta Argentina, la democracia centralista, mientras que el federalismo ha sido el régimen feliz de Norteamérica.

Bolívar expresa a su vecino de Jamaica que la única voluntad que puede derrotar al español es la unión y ella, ahora, continúa ausente, porque intereses foráneos han favorecido esta especie de federalismo americano. La doctrina Monroe se ha hecho realidad: Indoamérica es para los norteamericanos. Bolívar escribe al final, en su carta: Cuando los sucesos no están asegurados, cuando el estado es débil y cuando las empresas son remotas, todos los hombres vacilan, las opiniones se dividen, las pasiones las agitan y los enemigos las animan para triunfar por este fácil medio (Bolívar, 1993, p. 32). Esta sigue siendo nuestra visión de la realidad actual, la cual devolvemos a Bolívar más preocupados que él. iCuán lejos permanecen los sueños de libertad! Y eso que Bolívar soñaba con Estados fuertes, así como nosotros aspiramos a la madurez sólo como un medio para las realizaciones mayores del espíritu. La fatalidad ha crecido en forma desmedida y así seguimos escribiendo esta carta inacabada de Jamaica. Sin cultivar las virtudes y los talentos que conducen a la gloria" (Bolívar, 1993, p. 32). Sigue perteneciendo al futuro todo deseo para nuestra América mestiza. ¿Cómo podremos seguir creyendo, con Bolívar, con Martí, con Mariátegui, con Rodó, con Paz, con Fuentes y con todos los pensadores de Indoamérica, que algún día "seguiremos la marcha majestuosa hacia las grandes prosperidades a que está destinada la América meridional; entonces la ciencias y las artes que nacieron en el Oriente y han ilustrado la Europa volarán a Colombia 
Arboleda González, C. (2019). La Carta de Jamaica. Inventario de un genocidio y análisis del sueño frustrado de libertad. Revista Estudios Latinoamericanos, 44-45, 103-110.

libres, que las convidará con un asilo" (Bolívar, 1993, p. 32).

\section{Sigamos buscando la utopía en la América mestiza}

Los grandes sueños, aunque no se cumplan, han tratado de impedir el destino adverso de los pueblos. ¿Qué nos espera, si llevamos más de 500 años irrigando estos parajes de la tierra con sangre? Nunca tuvimos el sentido trágico de la vida, el que sí se dio, según Unamuno, en España que tenía la mirada fija en las penas y glorias del pasado (Fuentes, 1997, p. 500). Pero el despojo y la usurpación hicieron que siguiéramos creciendo a la inversa, con una conciencia desgraciada, melancólica, que clama en la música, en el arte y en los actos y actitudes políticas por la regresión y el fracaso. No existe vocación por la búsqueda de trascendencia y por eso nos hemos refugiado en una novela, en una mitología para ser contada en noches interminables, sin luz eléctrica, sin agua potable, sin educación; nos engañamos y por eso los Estados favorecen, en forma descarada, la búsqueda de un protagonismo falso. Tenemos necesidad ahora de campeones mundiales, de premios y de menciones para encubrir la cruda realidad descompuesta.

Después de haberse perdido la Gran Colombia, por rencillas de parroquia y por una lucha mezquina entre ciudadanos y militares, sin mayoría de edad, inventamos, tardíamente, y sin ningún resultado positivo, el Pacto Andino, Mercosur y Unasur. Pero estos remedos de unión delatan la incapacidad de estas democracias para manifestar su voluntad de autodeterminación.
Ahora nos unen grandes espectáculos deportivos y artísticos con los cuales pagamos para emplear un poco a los pueblos consumistas del Norte y del Viejo Mundo. Sin embargo, nuestro único camino sigue siendo la democracia. Por eso compartimos las apreciaciones de Octavio Paz: La democracia nos llegó tarde y ha sido desfigurada y traicionada una y otra vez. Ha sido débil, indecisa, revoltosa, enemiga de sí misma, fácil a la adulación del demagogo, corrompida por el dinero, roída por el favoritismo y el nepotismo. Sin embargo, casi todo lo bueno que se ha hecho en América Latina, desde hace siglo y medio, se ha hecho bajo el régimen de la democracia o, como en México, hacia la democracia. Falta mucho por hacer (Paz, 1995, p. 94).

Nadie sabe, ni el más alto de los sabios, quién creó el mundo y ahora, pienso, que fuimos los utopistas como nosotros, que seguimos creciendo desesperanzados. Bolívar, Martí, Rodó, Mariátegui, Paz se han ido, pero continuamos aspirando a ver cumplida la idea de utopía de Pedro Henríquez Ureña: El hombre universal con que soñamos, a que aspira nuestra América, no será descastado; sabrá gustar de todo, apreciar todos los matices, pero será de su tierra; su tierra y no la ajena, le dará el gusto intenso de los sabores nativos, y esa será su mejor preparación para gustar de todo lo que tenga sabor genuino, carácter propio (Henríquez Ureña, 1989, p. 7-8). Mientras tanto sigamos admirando y estudiando a los mejores de nuestros hombres, para nosotros, hijos de los Andes, del cóndor, de las nieves perpetuas, de los llanos, de los dos mares, en fin, hijos del Continente de los Siete Colores. 


\section{Referencias}

Bolívar, S. (1993). Carta de Jamaica. En Fuentes de la cultura latinoamericana, Leopoldo Zea (Compilador), Tomo I. Ciudad de México: Fondo de Cultura Económica.

Fuentes, C. (1997). El espejo enterrado. Ciudad de México: Editorial Taurus.

Henríquez Ureña, P. (1989). La utopía de América. Barcelona, Biblioteca Ayacucho, reimpresión.

Mariátegui, J. C. (s.f.). 7 ensayos de interpretación de la realidad peruana. Barcelona: Biblioteca Ayacucho.

Paz, O. (1995). Iberoamérica, en Ideas y costumbre I, Obras completas, tomo 9, segunda edición. Ciudad de México: Fondo de Cultura Económica. 